work, insufficient vacation time, affected personal health, unexpected or short notice in shift arrangements, low respect at work, and salary and benefits.

Conclusions The problem of high percentage of nurses considering leaving job has been real. This problem was related to high burnout and conflicting with family needs in nurses, most likely caused by high work load and problems in work arrangements.

\section{COMBINED EFFECT OF CIGARETTE SMOKING AND NON- FERROUS METAL EXPOSURE IN THE DEVELOPMENT OF DIGESTIVE DISEASE IN INDUSTRY WORKERS}

${ }^{1}$ Eniko Judit Viragh, ${ }^{2}$ Karoly Andras Viragh, ${ }^{3}$ Claudia Munteanu. ${ }^{1}$ University of Medicine and Pharmacy, Targu-Mures, Romania; ${ }^{2}$ Olive-View UCLA Medical Center, Los Angeles, USA; ${ }^{3}$ Authority of Preventive Medicine, Sibiu, Romania

\subsection{6/oemed-2014-102362.296}

Objectives Purpose of the study: (1) to determine the prevalence of digestive diseases in workers in non-ferrous metallurgy, and (2) to evaluate the effect of cigarette smoking in the development of digestive diseases in exposed workers.

Method A retrospective combined cross-sectional and case-control study was performed. Industry workers from a nonferrous plant and controls were monitored for an 8-year period. All workers received regular clinical examinations: evaluation for "smoking status, "occupational exposure to $\mathrm{Pb}$ and $\mathrm{Cd}$, *digestive disease using an epidemiological survey. Four representative groups were selected: Group (1)-exposed smokers, Group (2)non-exposed smokers, Group (3)-exposed non-smokers, Group (4)-non-exposed non-smokers. The prevalence of digestive diseases was determined in each group. Linear regression analysis was used to assess the correlation between the levels of exposure and biomarkers of exposures, as well as between the amount of smoking and the burden of digestive disease.

Results During the studied period, Pb\&Cd levels in the air of all workplaces were persistently high $\left(\mathrm{Pb}=0.9-13.3 \mathrm{mg} / \mathrm{m}^{3} ; \mathrm{Cd}=\right.$ $0.3-1.3 \mathrm{mg} / \mathrm{m}^{3}$ ). Clinical examination identified the classic symptoms of chronic occupational intoxication with $\mathrm{Pb}$. There was a relatively high prevalence of smoking in group (1) and (2). The prevalence of digestive disease was significantly higher in exposed smokers. Linear regression analysis showed close relationship between the studied parameters.

Conclusions There is high prevalence of smoking and digestive disease in industry workers. Cigarette smoking may act as a confounder in the assessment of the severity of occupational disease related to noxious metal exposure in industry workers. The goal for all facilities and workers is to minimise smoking and occupational exposure to noxious agents.

\section{PREVALENCE OF SPONTANEOUS ABORTION IN WORKERS IN THE WOOD-PROCESSING INDUSTRY}

${ }^{1}$ Eniko Judit Viragh, ${ }^{2}$ Karoly Andras Viragh, Josif Laczka. ${ }^{1}$ University of Medicine and Pharmacy, Targu-Mures, Romania; ${ }^{2}$ Olive-View UCLA Medical Center, Los Angeles, USA; ${ }^{3}$ Authority of Preventive Medicine, Satu-Mare, Romania

\subsection{6/oemed-2014-102362.297}

Objectives The purpose of the study was to determine the prevalence of spontaneous abortion in workers exposed to organic solvents in the wood-processing industry.

Method A retrospective combined cross-sectional and case-control study was performed. Female workers from a wood- processing factory were monitored for a 10 -year period through periodic clinical exams and epidemiologic surveys. Only fertile female workers were monitored, infertile workers (postmenopausal, status post hysterectomy) were excluded. The level of organic solvents was measured in the air during the study period. Each exposed fertile female was matched to a corresponding control subject without exposure to organic solvents. The prevalence rate of spontaneous abortions was evaluated in both groups.

Results During the study period, the organic solvents levels exceeded several times the maximal admissible concentrations. There were 366 exposed fertile female workers. The prevalence of spontaneous abortions in the exposed group was higher compared to the reference group and general public. The majority of abortions happened in the first trimester of pregnancy.

Conclusions Long-term exposure to organic solvents may cause decreased fertility in female workers. The goal for all facilities and workers is to minimise occupational exposure to noxious agents.

\section{CAN WORKPLACE CHEST X-RAY SURVEILLANCE PROGRAMS SHED LIGHT ON WORKERS' INJURIES? PREVALENCE AND PREDICTORS OF RIB FRACTURES AMONG ACTIVE AND FORMER UKRAINIAN COAL MINERS}

1,2Judith M Graber, ${ }^{2}$ Robert A Cohen, ${ }^{3}$ Angela Basanets, ${ }^{3}$ Yuri Kundiev, ${ }^{4}$ Vladimir Mukhin, ${ }^{5}$ Olga Lysenko, ${ }^{6}$ Alexander Zvinchuk, ${ }^{2}$ Daniel Hryhorczuk. ${ }^{1}$ Rutgers University, Environmental and Occupational Health Institute, Piscataway, New Jersey, USA; ${ }^{2}$ University of Illinois at Chicago, Chicago, Illinois, USA; ${ }^{3}$ nstitute of Occupational Health, Kiev, Ukraine; ${ }^{4}$ Research Institute for Medico-Ecological Problems of Donbass and Coal Industry, Donetsk, Ukraine; ${ }^{5}$ Hospital \#25, Donetsk, Ukraine; ${ }^{6}$ University of Illinois, Kiev, Ukraine

\subsection{6/oemed-2014-102362.298}

Objectives Chest x-ray surveillance programs for pneumoconiosis are well established public health tools. Data on rib fractures, part of the ILO system of classification, may shed light on injuries in these populations. We sought to determine the prevalence of rib fractures from a cross-sectional study of current and former Ukrainian coal miners.

Method Between 2001 and 2003, coal miners with at least five years of underground mining experience were randomly selected from employment records of 7000 current and 9000 former miners from three mines. CXRs were read by two NIOSH Breaders. Interviewers collected work and smoking history. The prevalence and predictors of at least one rib fracture with $95 \%$ confidence intervals [95\% CIs] was estimated using univariate methods and logistic regression.

Results Average age was 47.1 years among the 598 active miners and 56.9 years among the 468 former miners. Total mining tenure and years of work at the coal face were similar in both groups, about 20 and 8 years respectively. The prevalence of rib fractures was almost twice as high in former compared with current miners $(15.5 \%$ [11.6, 19.5\%] vs. $7.9 \%$ [5.6, 13.3\%], respectively). Prevalence increased with age among active miners; among former miners prevalence was highest in 45 to 55 year olds.

Conclusions CXR surveillance for pneumoconiosis may have use in monitoring injury among miners. While the prevalence of rib fracture appeared high in this population, caution is warranted interpreting our findings: no comparison groups exist and the use of this methodology for characterising injury prevalence is untested. 


\section{DIMENSIONAL STRUCTURE OF THE JOB CONTENT QUESTIONNAIRE-JCQ AMONG HEALTH WORKERS OF BAHIA, BRAZIL}

${ }^{1}$ Kionna Bernardes, ${ }^{1}$ Fernando Carvalho, ${ }^{2}$ Tânia Araújo. ${ }^{1}$ Federal University of Bahia, Salvador, Bahia, Brazil; '2State University of Feira de Santana, Feira de Santana, Bahia, Brazil

10.1136/oemed-2014-102362.299

Objectives The aim of this study was to evaluate the dimensions of the JCQ among healthcare workers

Method A validation study with 3055 health workers was conducted. Factor analysis was employed through the principal components method. For extraction of factors, parallel analysis was performed using the Monte-Carlo simulation. For the technique of factor analysis, the verification of the sampling adequacy of the studies was performed by measuring the Kaiser-Meyer-Olkin (KMO). The PROMAX oblique rotation was applied for a better understanding of the values, assuming mutual correlation between the factors.

Results There was adequacy of the data for factor analysis according to the criteria of the KMO test (0.93). Four dimensions, which together explained $100 \%$ of the total variance, were extracted. The first dimension was composed of physical and emotional demands by means of the social support from coworkers. The second dimension represented items of control over work; the third dimension consisted of items of social support of the headship; the fourth dimension presented items regarding the use of skills.

Conclusions The number and dimensions of the frame captured by an instrument depend on the set of subjective symptoms to be investigated. In spite of the technical/methodological advances of analysis, there are still limitations in the use of instruments to measure subjective constructs in the occupational sphere.

\section{PHYSIOLOGICAL ASPECTS OF LOAD CARRIAGE ACTIVITY DONE BY FOOD GRAIN HANDLING WORKERS IN INDIA}

Hema Bhatt, Promila Sharma. G. B. Pant University of Agriculture and Technology, Pantnagar, Uttarakhand, India

\subsection{6/oemed-2014-102362.300}

Objectives There are many rice mills and food grain depots where a large number of workers are engaged for processing paddy and rice, storage and distribution. Lifting, carrying and depositing sacs of food grain are the major jobs carried out by these workers. The present study was undertaken to evaluate the workers with respect to the workload, energy expenditure and musculoskeletal pain or discomfort resulting out of work practice.

Method Present study was conducted at Rudrapur city in Uttarakhand state of India. Representative samples of 40 rice mill workers engaged under Food Corporation of India were taken for study. Descriptive cum experimental research design were chosen to find work profile, for identification of risks factors at work places and to assess the physiological workload of the rice mill workers.

Results Average peak heart rate of the rice mill workers suggested the workload as moderate to very heavy. Their average energy expenditure values also indicated the workload as moderate to heavy. Musculoskeletal pain or discomfort was maximally reported in knee by $64.5 \%$ depot workers whereas low back and knee was reported by $35.5 \%$ rice mill workers. Besides the weight of the sac, awkward postures like bending and twisting of trunk adopted frequently causes the problem.

Conclusions A significant problem associated with manual handling activities involving loading and unloading tasks is the fact that they are the primary cause of overexertion injuries. Further studies and rationalisation of work method may improve the health and safety of the workers.

\section{IS PERCEIVED STRESS RELATED TO AN INCREASE IN SALIVARY CORTISOL}

Samuel Fink, Jens Peter Bonde, Marianne Agergaard Vammen, Sigurd Mikkelsen, Jane Frølund Thomsen. Department of Occupational- and Enviromental Health, Bispebjerg Hospital, Copenhagen, Denmark

\subsection{6/oemed-2014-102362.301}

Objectives Perceived Stress is a suspected cause of many psychological and physical illnesses. However it remains to be discovered what physiological measures are involved. While it is widely known that acute stress leads to an increase in cortisol levels, the findings in prolonged stress research have not been consistent. This study explores the association between Perceived Stress and salivary cortisol levels using the largest population ever used in this field.

Method 4467 public employees in the PRISME cohort in 2007. 3217 of those did a similar follow up study in 2009 .

A 4-item Danish version of the PSS-scale was used to measure perceived stress and operationalized as the average score. Salivary cortisol samples were taken at $30 \mathrm{~min}$ post awakening and at $8 \mathrm{pm}$. A mean value of cortisol was calculated. In our analysis we applied logarithmic transformation to the concentrations.

Results Linear regression analysis done for the association between PSS-score and salivary cortisol levels showed no significant association between the two. For cortisol mean the regression resulted in $\beta=-0.005(\mathrm{Cl}:-0.036-0.026)$ in 2007 and -0.010 $(\mathrm{Cl}:-0.047-0.028)$ in 2009 . Cortisol morning analysis resulted in $\beta=-0.013(\mathrm{Cl}:-0.050-0.023)$ in 2007 and $\beta=-0.003(\mathrm{Cl}$ : $0.048-0.042)$ in 2009 . Cortisol evening analysis resulted in in $\beta=-0.000(\mathrm{Cl}:-0.042-0.042)$ in 2007 and $\beta=-0.007(\mathrm{Cl}$ : $0.047-0.061$ ) in 2009 .

Conclusions Overall this study does not provide any evidence that perceived stress is associated with salivary cortisol.

\section{AN INTERNATIONAL HISTORICAL COHORT STUDY OF WORKERS IN THE HARD-METAL INDUSTRY: MID-STUDY EPIDEMIOLOGY UPDATE}

${ }^{1}$ Gary Marsh, ${ }^{1}$ Jeanine Buchanich, ${ }^{1}$ Sarah Zimmerman, ${ }^{2}$ Kathleen Kennedy, ${ }^{2}$ Nurtan Esmen, ${ }^{3}$ Hanns Moshammer, ${ }^{4}$ Peter Morfeld, ${ }^{4}$ Thomas Erren, ${ }^{5}$ Magnus Svartengren, ${ }^{6}$ Hakan Westberg, ${ }^{7}$ Damien McElvenny, ${ }^{7}$ John Cherrie. ${ }^{1}$ University of Pittsburgh, Pittsburgh, PA, USA; ${ }^{2}$ University of Illinois at Chicago, Chicago, IL, USA; ${ }^{3}$ Medical University of Vienna, Vienna, Austria; ${ }^{4}$ University of Cologne, Cologne, Germany; ${ }^{5}$ Uppsula University, Uppsula, Sweden; ${ }^{6}$ Orebro University, Orebro, Sweden; ${ }^{7}$ Institute of Occupational Medicine, Edinburgh, UK

\subsection{6/oemed-2014-102362.302}

Objectives A multinational occupational epidemiological study of workers exposed to tungsten carbide with a cobalt binder (WCCo) is underway in the US and Europe. The epidemiological component will investigate total and cause-specific mortality risks and exposure-response relationships with focus on lung 